\title{
Tuning luminescence intensity of RHO6G dye using silver nanoparticles
}

\author{
SUCHITA KALELE, APARNA C DESHPANDE, SHASHI BHUSHAN SINGH and \\ S K KULKARNI* \\ DST Unit on Nanoscience and Nanotechnology, Department of Physics, University of Pune, Pune 411007 , India
}

\begin{abstract}
The photoluminescence (PL) from rhodamine (RHO6G) dye dispersed in ethanol has been studied in the presence of different amounts of citrate stabilized silver nanoparticles of size, $\sim 10 \mathrm{~nm}$. Enhancement as well as quenching of luminescence intensity has been observed and it was found that luminescence intensity can be tuned by adding various amounts of silver nanoparticles to the RHO6G dye dispersion. The luminescence spectra of dye consist of two peaks at $440 \mathrm{~nm}$ and $550 \mathrm{~nm}$. Peak at $440 \mathrm{~nm}$ shows an enhancement in intensity at all the concentrations of added silver nanoparticles with the maximum intensity for dye with $0 \cdot 25 \mathrm{ml}$ silver nanoparticles $(82 \%$ enhancement in the luminescence intensity). PL intensity of intense peak at $550 \mathrm{~nm}$ of dye molecules was found to be quenched in presence of silver nanoparticles and maximum quenching was found to be $41 \%$ for the dye with $1 \mathrm{ml}$ silver nanoparticles. However, for lowest concentration of silver nanoparticles viz. $(0.01 \mathrm{ml})$, enhancement in intensity was observed $(13 \%$ enhancement than the dye molecules). The quenching as well as enhancement in the intensity can be understood by considering the possibility of three different phenomena. It has been reported earlier that when metal nanoparticles are in close proximity to the fluorophores, quenching of luminescence occurs, whereas when metal nanoparticles are located at certain distance, enhancement in luminescence is observed. This effect has been explained by coupling of surface plasmon resonance from metal nanoparticles with fluorophore, resulting in the increase of excitation and emission rate of the fluorophore in the localized electromagnetic field. The quenching and enhancement of luminescence intensity of the dye molecules can also be explained as the transfer of electrons from dye to the silver nanoparticles and to an extent it can be attributed to the aggregation of dye molecules upon addition of silver nanoparticles.
\end{abstract}

Keywords. Luminescence; optical properties; metal nanoparticles.

\section{Introduction}

Organic dyes have been studied extensively due to their luminescence properties and possibility to tune their properties by coating with another material (encapsulating shell) or by localizing near metal surfaces (Geddes et al 2003; Ethiraj et al 2005). Among organic dyes, rhodamine $6 \mathrm{G}$ (RHO6G) dye is one of the most important dyes. This dye has remarkably high photostability and high quantum yield (0.95), therefore, often used as a laser dye. However, this dye photobleach very fast upon exposure to the light source and efforts have been dedicated to overcome this problem by doping them in polymer matrix (George et al 1999).

Earlier, the luminescences of dye molecules have been studied by encapsulating them with silica shell (Imhof et al 1999; Ethiraj et al 2005). It was found that coating these molecules with silica, photostabilizes them. Tuning the luminescence intensity of dye molecules near a metal surface was studied by Drexhage in as early as 1970 ,

\footnotetext{
*Author for correspondence (skk_surface@yahoo.com)
}

leading to various reports on interaction of fluorophores with metal nanoparticles or surfaces (mostly silver) displaying various spectral changes such as enhancement in luminescence intensity, photostability, quantum yield etc (Lakowicz 2001). It has been found that when metal nanoparticles are in close proximity to the fluorophores, quenching of luminescence occurs, whereas when metal nanoparticles are located at certain distance, enhancement in luminescence is observed (Zhang and Lakowicz 2006). These effects have been explained by coupling of surface plasmon resonance from metal particles and fluorophore. Zhang and Lakowicz (2005) studied the fluorescence of phenyl phenanthridine dye on silver nanoparticles and could notice an enhancement in the luminescence by a factor of two. Geddes et al (2003) examined the effect of metallic silver colloids on the luminescence properties of indocyanine green dye and found a 30 fold increase in the intensity of dye molecules with decreased life times and increased photostability. Ishikawa and Okubo (2003, 2005) have investigated the spectrally narrowed emission from rhodamine $6 \mathrm{G}$ infiltrated in synthetic opals. Synthetic opals have interconnected nanoscale voids in which silver nanoparticles can be anchored. When dye molecules are 
dispersed in these opals, they are within a distance of only few tens of nanometer from metal surface. Effect of surface plasmon resonance of silver nanoparticles on dye molecules have been studied and narrowing of spectral line width (one tenth lower than without silver) in the emission spectra from the dye molecules was observed.

Theoretical studies have been carried out on absorption and luminescence of dye molecules adsorbed on silver and gold nanoparticles or surfaces. Wang and Kerker (1982) found that due to interaction of metal and dye in core shell particles splitting of extinction bands occurs. Enhancement also has been reported due to such interaction. Quenching of the luminescence of dye molecules adsorbed on a smooth Ag surface was observed by Ritchie and Burstein (1981).

However, all these reports are limited to metal surfaces and thin films and study of the behaviour of dispersion of dye molecules in presence of colloidal metal nanoparticles would be interesting. Here, in this report, enhancement as well as quenching of luminescence intensity of RHO6G dye upon interaction with $10 \mathrm{~nm}$ size citrate stabilized silver nanoparticles is discussed. It was found that luminescence intensity can be tuned by adding various amounts of silver nanoparticles in the ethanolic dispersion of dye molecule.

\section{Experimental}

Silver nanoparticles were synthesized by chemical reduction method using tri-sodium citrate. In a typical synthesis procedure, $50 \mathrm{ml}$ of $2 \times 10^{-3} \mathrm{M}$ silver nitrate $\left(\mathrm{AgNO}_{3}\right)$ was heated at $80^{\circ} \mathrm{C}$ for $15 \mathrm{~min}$. To this warm solution, $50 \mathrm{ml}$ of $2 \times 10^{-2} \mathrm{M}$ tri-sodium citrate $\left(\mathrm{Na}_{3} \mathrm{C}_{6} \mathrm{H}_{5} \mathrm{O}_{7}\right)$ was added and the resulting mixture was refluxed at $80^{\circ} \mathrm{C}$ for $30 \mathrm{~min}$. After about $15 \mathrm{~min}$, initially clear solution of silver nitrate turned pale yellow and finally to golden yellow colour indicating the formation of silver nanoparticles. TEM analysis revealed that the silver nanoparticles

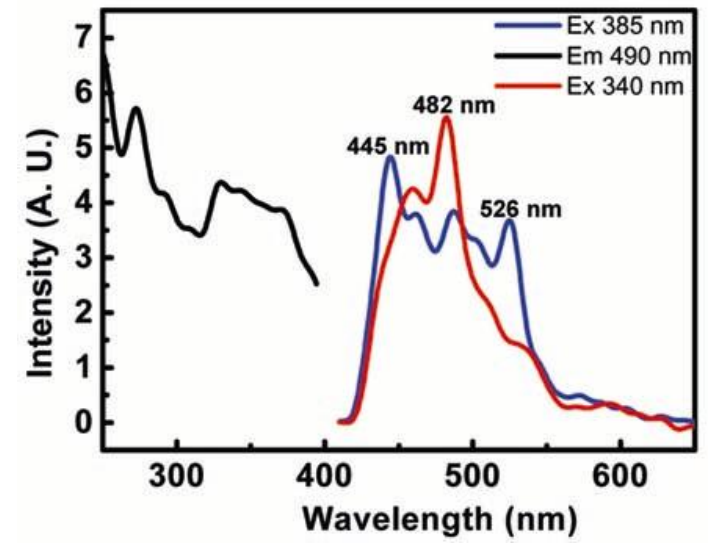

Figure 1. Luminescence spectra of $\mathrm{Ag}$ nanoparticles. synthesized by this procedure had a size of $\sim 10 \mathrm{~nm}$. These particles were stabilized by the formation of electric double layer of adsorbed citrate and/or nitrate ions and their corresponding cations around them, hence they were very sensitive to charge transfer interactions.

Rhodamine (RHO6G) dye $\left(\mathrm{C}_{28} \mathrm{H}_{31} \mathrm{~N}_{2} \mathrm{O}_{3} \mathrm{Cl}\right)$ was dispersed uniformly in ethanol and to this solution measured amount of aqueous dispersion of silver nanoparticles was added viz. $1 \mathrm{ml}, 0.5 \mathrm{ml}, 0.25 \mathrm{ml}, 0.2 \mathrm{ml}, 0.1 \mathrm{ml}$ and $0.001 \mathrm{ml}$. Photoluminescence spectra (PL) were recorded using Perkin Elmer LS 55 spectrophotometer and UV-Vis absorption spectra were recorded using Ocean Optics (model DT 1000 CE 376) spectrophotometer.

\section{Results and discussion}

First report on luminescence from metals has been given by Mooradian (1969). The band structure of metal has been represented by a simplified model which includes an $s-p$ conduction band and two sets of occupied $d$ bands. The excitation involves a transition from states in the upper $d$ bands to unoccupied levels in the $s-p$ band at and above the Fermi energy. The emission arises from direct recombination of conduction band electron below the Fermi energy with holes in the $d$-band. Emission and excitation spectra for silver nanoparticles are shown in figure 1. Excitation of silver nanoparticles with $385 \mathrm{~nm}$ results in broad emission band consisting of several peaks between 445 and $550 \mathrm{~nm}$. Excitation of the same sample with photons of high energy $(340 \mathrm{~nm})$ results in narrowing of the spectra with a sharp peak at $482 \mathrm{~nm}$.

Interaction of rhodamine dye molecule with silver nanoparticles is schematically shown in figure 2 . This molecule has two amine $(\mathrm{NH})$ groups with which it can bind to silver nanoparticles. Among these two amino groups, one group is more electropositive and can bind to silver nanoparticles preferentially to form dye silver nanoparticles complex. Due to affinity of dye molecule with silver nanoparticles, electron transfer mechanism becomes easier as can be noticed from luminescence measurements.

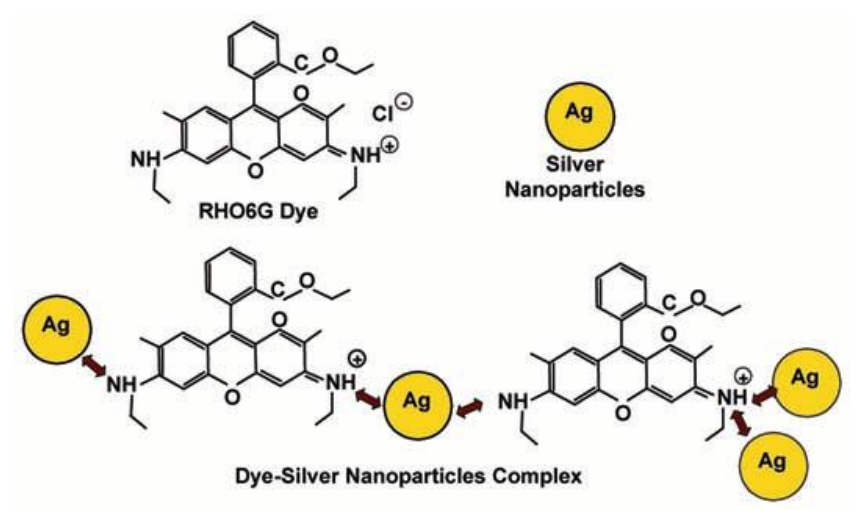

Figure 2. A schematic representation of the formation of dyeAg nanoparticles complex. 
UV-Vis absorption spectra from dye and dye molecules with silver nanoparticles are shown in figure 3. Citrate stabilized silver nanoparticles show an intense absorption peak also known as surface plasmon resonance peak at $440 \mathrm{~nm}$ (as shown in figure 3), presence of which is explained as the resonance between the collective oscillations of conduction electrons with incident electromagnetic field (Mulvaney 1996). Dye molecules show an intense peak at around $530 \mathrm{~nm}$, position and intensity of the same remain unchanged at addition of lower concentration of silver nanoparticles. For higher concentration of silver nanoparticles viz. $0.5 \mathrm{ml}$ and $1 \mathrm{ml}$, presence of broad hump at $440 \mathrm{~nm}$ along with a peak at $530 \mathrm{~nm}$ could be noticed. The absorption spectra of dye molecules with higher concentration of silver nanoparticles $(0.5 \mathrm{ml}$ and $1 \mathrm{ml})$ are found to be the sum of the spectra recorded for dye and silver nanoparticles separately. Similar results could be noticed by Franzen et al (2002) while studying the optical properties of various dye molecules (such as crystal violet, methyl green, indocynine green, rhodamine B etc) adsorbed on citrate stabilized gold nanoparticles.

Figure 4 shows luminescence spectra from dye and dye molecules with variable concentration of silver nanopar-

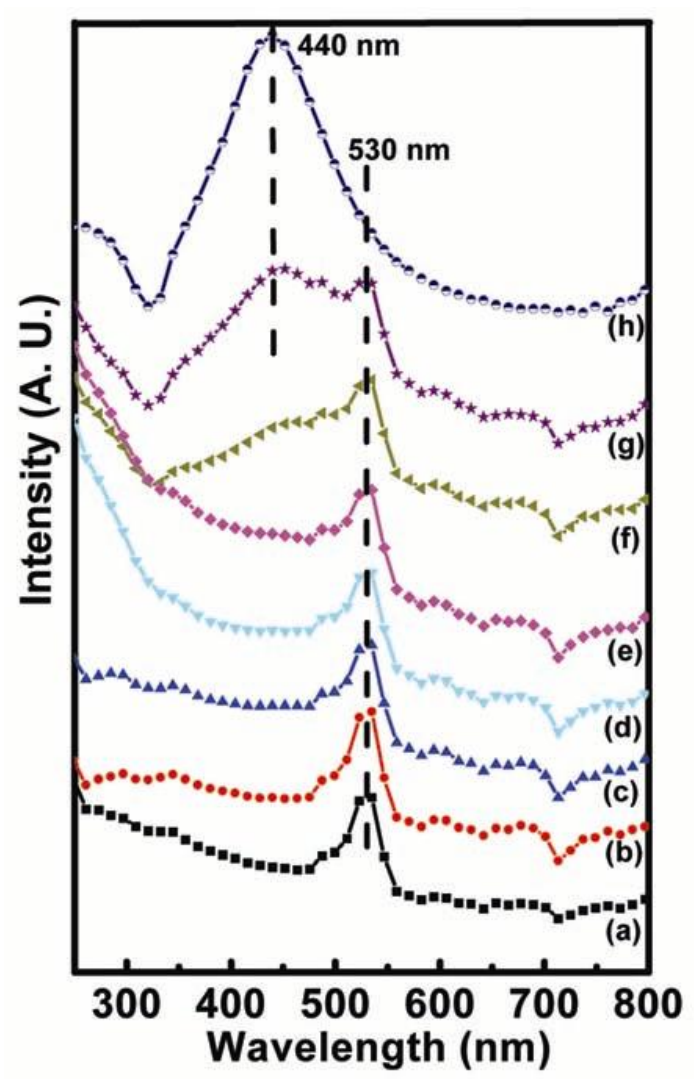

Figure 3. UV-Vis absorption spectra of (a) bare dye, (b) dye$\mathrm{Ag}(0.001 \mathrm{ml}),(\mathbf{c})$ dye-Ag $(0.1 \mathrm{ml}),(\mathbf{d})$ dye-Ag $(0.2 \mathrm{ml}),(\mathbf{e})$ dye-Ag $(0.25 \mathrm{ml}),(\mathbf{f})$ dye $-\mathrm{Ag}(0.5 \mathrm{ml}),(\mathbf{g})$ dye $-\mathrm{Ag}(1 \mathrm{ml})$ and (h) bare $\mathrm{Ag}$. ticles in the solution at excitation wavelength, $385 \mathrm{~nm}$. The emission spectra consist of two distinct peaks at $550 \mathrm{~nm}$ and $440 \mathrm{~nm}$. Peak at $440 \mathrm{~nm}$ shows an enhancement in intensity at all the concentrations with the maximum intensity for dye with $0.25 \mathrm{ml}$ silver nanoparticles. It was found that on addition of $0.25 \mathrm{ml}$ silver nanoparticles in RHO6G dye, can enhance the luminescence intensity by $82 \%$. For peak at $550 \mathrm{~nm}$ enhancement in intensity for only one concentration viz. $0.001 \mathrm{ml}$ and quenching of peak intensity for all other concentrations was observed. This peak at $550 \mathrm{~nm}$ shows $13 \%$ enhanced intensity for dye with $0.001 \mathrm{ml}$ silver nanoparticles, whereas $41 \%$ quenching of luminescence intensity for $1 \mathrm{ml}$ silver nanoparticles was observed. A graph of peak intensity as a function of amount of silver nanoparticles is plotted in inset of figure 4 . The graph for peak at $550 \mathrm{~nm}$ shows a gradual reduction in intensity as the amount of added silver particles increases whereas for $440 \mathrm{~nm}$ peak intensity it was found to be maximum for $0.25 \mathrm{ml}$ silver nanoparticles. Earlier, enhancement of luminescence was observed by Zhang et al (2004) for fluorophores in the vicinity of silver nanoparticles due to aggregation. At the same time enhancement and quenching of luminescence has been explained in terms of electron transfer from fluoropore to the silver nanoparticles (Lakowicz et al 2004). Luminescence behaviour of fluorophores also gets affected by SPR, arising from metal nanoparticles. The plasmon resonance of the metal nanoparticles represents the existence of a localized electromagnetic field near the metal nanoparticle. In case of spherical nanoparticles of size between 10 and $200 \mathrm{~nm}, 100-10,000$ times enhancement of the electric field is observed near the particle surface (Haes et al 2005). When a fluorophore is placed in the close vicinity of metal nanoparticle, increase in excitation and emission rate is observed due to the pre-

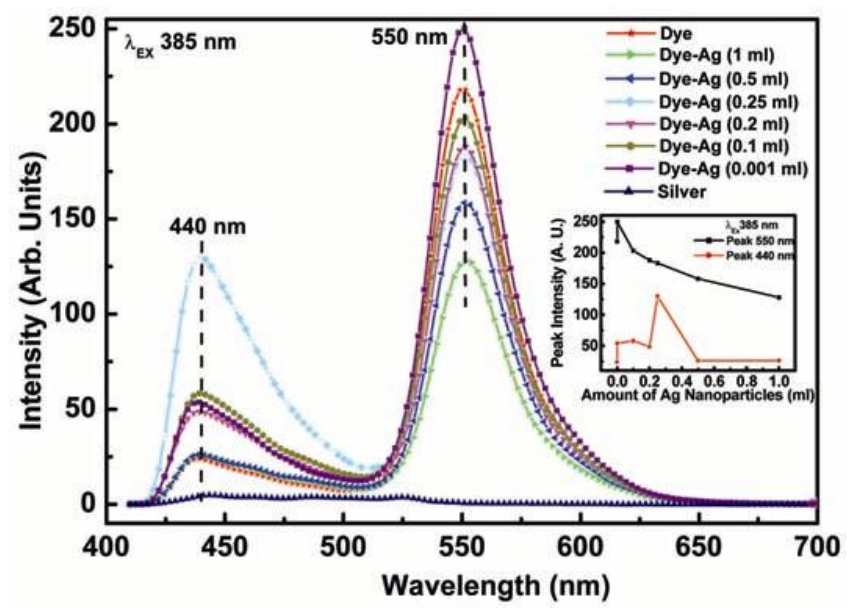

Figure 4. Emission spectra from dye and dye molecules with variable concentration of silver nanoparticles at $385 \mathrm{~nm}$ excitation wavelength. (Inset: a plot of peak intensity as a function of amount of silver nanoparticles added). 
sence of this localized electromagnetic field as can be seen from the emission spectra. Similar trend in emission spectra from dye and dye molecules with variable concentration of silver nanoparticles at $340 \mathrm{~nm}$ excitation wavelength is observed.

Luminescence properties of dye molecule can be tuned by adding small quantities of colloidal silver nanoparticles. Coupling of dye molecules with silver nanoparticles can lead to many interesting optical and electronic properties and exploited in a variety of applications such as biological sensing, light emitting diodes etc.

\section{Acknowledgements}

Authors would like to thank DST India, CSIR India and UGC India, for constant support.

\section{References}

Drexhage K H 1970 J. Lumin. 12693

Ethiraj A, Hebalkar N, Kharrazi S, Urban J, Sainkar S R and Kulkarni S K 2005 J. Lumin. 11415
Franzen S, Folmer J C W, Glomm W R and O'Neal R 2002 J. Phys. Chem. A106 6533

Geddes C D, Cao H, Gryczynsi I, Gryczynsi Z, Fang J and Lakowicz J R 2003 J. Phys. Chem. A107 3443

George N A, Aneeshkumar B, Radhakrishnan P and Vallabhan C P G 1999 J. Phys. D: Appl. Phys. 321745

Haes A J, Haynes C L, McFarland A D, Schatz G C, Van Duyne R P and Zou S 2005 MRS Bull. 30368

Imhof A, Megens M, Engelberts J J, De Lang D T N, Sprik R and Vos W L 1999 J. Phys. Chem. B103 1408

Ishikawa K and Okubo T 2003 Appl. Phys. Lett. 832536

Ishikawa K and Okubo T 2005 J. Appl. Phys. 98043502

Lakowicz J R 2001 Anal. Biochem. 2981

Lakowicz J R, Geddes C D, Gryczynski I, Malicka J, Gryczynski Z, Aslan K, Lukomska J, Matveeva E, Zhang J, Badugu $\mathrm{R}$ and Huang J 2004 J. Fluorescence 14425

Mooradian A 1969 Phys. Rev. Lett. 22185

Mulvaney P 1996 Langmuir 12788

Ritchie G and Burstein E 1981 Phys. Rev. B24 4843

Wang D -S and Kerker M 1982 Phys. Rev. B25 2433

Zhang J and Lacowicz J R 2005 J. Phys. Chem. B109 8701

Zhang J and Lacowicz J R 2006 J. Phys. Chem. B110 2387

Zhang J, Malicka J, Gryczynski I and Lakowicz J R 2004 Anal. Biochem. 33081 